\title{
Quality of Life among Post-Mastectomy with and without Reconstruction Breast Cancer Patients in Onkologi Surabaya Hospital
}

\author{
Cindy Angelina Limantara ${ }^{1 *}$, Ario Djatmiko ${ }^{2}$ \\ ${ }^{1}$ Department of Research and Development, Onkologi Surabaya Hospital, Surabaya, Indonesia \\ ${ }^{2}$ Department of Surgery, Onkologi Surabaya Hospital, Surabaya, Indonesia
}

\section{ARTICLE INFO}

Received : 01 August 2020

Reviewed : 15 September 2020

Accepted : 22 January 2021

\section{Keywords:}

breast cancer, quality of life, mastectomy, mastectomy with reconstruction

\author{
*Corresponding author: \\ Cindy Angelina Limantara \\ Department of Research and \\ Development, Onkologi Surabaya \\ Hospital, Surabaya, Indonesia \\ limantaradr@gmail.com
}

\begin{abstract}
Background: The quality of life (QoL) of breast cancer (BCa) patients is an outcome of therapy that is often overlooked. In real life, postoperative breast cancer patients experience deep trauma in view that breasts are a symbol of femininity, which are very valuable for any female. This study aims to compare the QoL in patients who received mastectomy only and mastectomy with reconstruction.
\end{abstract}

Methods: A retrospective comparative study of 25 post-mastectomy to 25 post-mastectomy with reconstruction BCa patients in Onkologi Surabaya Hospital. The subjects are patients who visited between July 2019 until March 2020, as many as 50 samples in accord with the inclusion and exclusion criteria. The assessment was performed using 3 instruments, including the hospital anxiety and depression scale (HADS), body image scale (BIS), and female sexual function index (FSFI). The collected data were analyzed using SPSS 15.0 for Windows.

Results: A significant difference in mean values was seen in body image and sexual function. Post-mastectomy BCa patients presented more body image disturbance $(p<0.05)$. Better sexual function is claimed by post-mastectomy with reconstruction BCa patients in Onkologi Surabaya Hospital $(p<0.05)$. Meanwhile, the depression and anxiety values did not differ significantly in both groups $(p>0.05)$.

Conclusions: Patients who underwent mastectomy and breast reconstruction have a better QoL in comparison with patients who received mastectomy only, in the domains of body image and sexuality function.

\section{INTRODUCTION}

In Indonesia, breast cancer (BCa) had the highest incidence of malignancy with 48,998 new cases and a mortality rate of $16.6 \%$ per 100,000 people in 2012 . Based on Globocan data in 2018, the incidence of BCa was 42.1 per 100,000 population. Based on the data from the American Cancer Society, although the incidence of $\mathrm{BC}$ a has increased in recent decades, there has been a decrease in mortality due to the advancement of therapeutic modalities in breast cancer [1].

Breast cancer surgical methods have developed progressively all over the years. Fisher introduced the Breast-conserving surgery (BCS) method that emphasized the multidimensional management of $\mathrm{BCa}$. Through his 20-year research, a conclusion was drawn that there was no significant difference in the survival rate of postmastectomy patients with post lumpectomy patients and radiotherapy [2].

BCS is the state of the art and a favorite treatment for patients with $\mathrm{BCa}$ as they do not have to lose breasts due to cancer. However, breast surgeons should carefully consider the contraindications to BCS, such as locally widespread disease, multicentricity, diffuse microcalcifications, 1st and 2nd-trimester pregnancy, patients with BRCA 1 and 2 gene mutations, and history of the previous radiotherapy in the chest area [2]. BCS also requires an optimal preoperative assessment and intraoperative pathology anatomy examination. 
At the Onkologi Surabaya Hospital, BCS also requires breast surgeons' consideration regarding the length of queues and limitations of radiotherapy facilities in Surabaya. Therefore, a mastectomy followed by a reconstruction procedure can be a therapeutic modality of choice. The superior cosmetic result can be a distinct advantage, and lots of literature implied better psychosocial values in patients with reconstruction [3].

Several studies had shown that women who underwent mastectomy without reconstruction often suffered discomfiture related to body image, self-esteem, and a decrease in QoL scores [2]. However, despite numerous studies and recommendations, nearly twothirds of BCa surgery procedures are still performed without BCS [4]. Decision-making is certainly influenced by several factors namely age, culture, and financial ability [2]. BCa influences all domains of QoL, and the most prominent are emotional and physical conditions, as well as the social function role. QoL measurement has become a well-accepted instrument to predict the outcome for cancer patients and an integral part of cancer patient management [5-7].

This is the first study in Onkologi Surabaya Hospital comparing the QoL in patients who received mastectomy and mastectomy with reconstruction. The objective of this study is to find out the comparison of QoL in patients who underwent mastectomy and mastectomy with reconstruction, as modalities of $\mathrm{BCa}$ treatment on postoperative patients'.

\section{METHODS}

This retrospective comparative study involved 25 post-mastectomy and 25 post-mastectomy with reconstruction $\mathrm{BCa}$ patients in Onkologi Surabaya Hospital. The subjects were taken consecutively based on their schedule of annual check-ups in Onkologi Surabaya Hospital from July 2019 until March 2020, as many as 50 samples in accord with the inclusion and exclusion criteria. Three assessment instruments were used, including the hospital anxiety and depression scale (HADS) [8], body image scale (BIS) [9], and female sexual function index (FSFI) [10].

The inclusion criterion to reduce psychological bias was a minimum of 1 year before the surgical procedure. To analyze sexual function, the inclusion criterion included married and sexually active female patients in a reproductive age range (15-49 years old). The exclusion criterion was patients with a history of psychiatric disorders and the presence of metastasis in other organs. Fifty participants were divided into 2 groups including, 25 post-mastectomy without reconstruction patients and 25 post-mastectomy with reconstruction patients.

The instrument in this study was a close questionnaire about the quality of life which included levels of anxiety and depression, body image, and sexual function. HADS questionnaire has a total of 14 questions, which are divided into 7 questions about anxiety and 7 questions about depression. Each question weighs $0-3$ points to be added per question category. The result is defined as normal (0-7), borderline (8-10), and abnormal (11-21).

The body image scale (BIS) questionnaire reflects a multifaceted concept including thoughts, emotions, and behavior [11]. BIS questionnaire consisted of 10 questions with a choice of 4 answers: no (value: 0 ), few (value: 1 ), moderate (value: 2 ), very (value 3 ). Total answers ranged from 0 to 30 with a total value of 0 depicting no symptoms or disturbances in body image and a higher value representing increasing symptoms or disturbances in body image.

To evaluate the function of sexuality, the FSFI questionnaire was used, which consisted of 19 questions about 6 major factors (desire, arousal, lubrication, orgasm, satisfaction, and pain) with a total of 36 points, where a value of $\geq 26.6$ indicates a good sexual function.

The collected data were analyzed using SPSS 15.0 for Windows. All significant values of Levene's Test for Equality of Variance (HADS $=0.272>0.05, \mathrm{BIS}=0.25$ $>0.05$, and $\mathrm{FSFI}=0.5>0.05$ ) indicated that the data of both groups were homogeneous. The mean value of HADS had a significant (2-tailed) value of $0.191>$ 0.05 , which means that there was no significant difference in both groups. The significant (2-tailed) of BIS $=0.022<0.05$, which means there is a significant difference in the mean value. The result showed that patients who underwent mastectomy alone have a higher mean indicating that post more symptoms of body image disturbance. The Sig. 2 tailed in FSFI value $=0.002<0.05$, indicating a significant difference in the mean value of both groups.

\section{RESULTS}

A total number of 50 respondents were approached and grouped into 2 groups based on the type of surgery. As listed in Table 1, the participant's ages who underwent mastectomy alone ranged from 31 to 49 years, with mostly in the $41-50$ years $(76 \%)$ and a mean age of 44.8 years. Women in the reconstruction group, on the other hand, were between the ages of 25 and 49 , with a mean age of 40,5 years and the majority between the ages of 41 and 50 (56\%).

The value of HADS was analyzed using an independent sample test, and it was found that the means in both groups did not differ significantly ( $p>0.05)$. Body image dissatisfaction was found to be significantly different between the two groups $(p<0.05)$. The result showed that patients who underwent mastectomy alone had a higher mean indicating more symptoms of body image disturbance.

The function of sexuality was evaluated with the FSFI instrument, where the standard mean value of $\geq 26.6$ 
indicated good sexual function (Table 2). An Independent sample test was used, and a significant difference between the two groups was found $(p<0.05)$. Patients who received mastectomy alone had a lower mean value than the standard mean value indicating a worse sexual function in comparison with the other group.

Table 1. Characteristic of the study population $(n=50)$

\begin{tabular}{|c|c|c|}
\hline $\begin{array}{l}\text { Characteristic } \\
\text { of the study } \\
\text { population }\end{array}$ & $\begin{array}{l}\text { Mastectomy } \\
\text { n (\%) }\end{array}$ & $\begin{array}{l}\text { Mastectomy with } \\
\text { Reconstruction } \\
\text { n (\%) }\end{array}$ \\
\hline \multicolumn{3}{|l|}{ Age } \\
\hline $21-30$ & 0 & $4(16 \%)$ \\
\hline $31-40$ & $6(24 \%)$ & 7 (28\%) \\
\hline $41-50$ & 19 (76\%) & $14(56 \%)$ \\
\hline \multicolumn{3}{|l|}{ Education } \\
\hline Elementary & 0 & $2(8 \%)$ \\
\hline JHS & $2(8 \%)$ & - \\
\hline SHS & $6(24 \%)$ & $7(28 \%)$ \\
\hline University & 17 (68\%) & $16(64 \%)$ \\
\hline \multicolumn{3}{|l|}{ Laterality } \\
\hline Right & 11 (44\%) & 15 (60\%) \\
\hline Left & $14(56 \%)$ & $10(40 \%)$ \\
\hline \multicolumn{3}{|c|}{ Pathological Grade } \\
\hline I & $3(12 \%)$ & $5(20 \%)$ \\
\hline II & $7(28 \%)$ & $5(20 \%)$ \\
\hline III & $15(60 \%)$ & $15(60 \%)$ \\
\hline \multicolumn{3}{|l|}{ Chemotherapy } \\
\hline Yes & $16(64 \%)$ & 19 (76\%) \\
\hline No & $9(36 \%)$ & $6(24 \%)$ \\
\hline \multicolumn{3}{|l|}{ Radiotherapy } \\
\hline Yes & 7 (28\%) & $9(36 \%)$ \\
\hline No & $18(72 \%)$ & $16(64 \%)$ \\
\hline \multicolumn{3}{|c|}{ Hormone Therapy } \\
\hline Yes & $19(76 \%)$ & $18(72 \%)$ \\
\hline No & $6(24 \%)$ & $7(28 \%)$ \\
\hline
\end{tabular}

Table 2. Assessments of the quality of life according to HADS, BIS, and FSFI

\begin{tabular}{llll}
\hline Group & HADS & BIS & FSFI \\
\hline M & $\mathrm{N}=25$ & $\mathrm{~N}=25$ & $\mathrm{~N}=25$ \\
& Mean $=7.24$ & Mean $=6.76$ & Mean $=25.47$ \\
& Standard & Standard & Standard \\
& Deviation & Deviation & Deviation \\
& $=6.59$ & $=4.48$ & $=4.79$ \\
M \& R & $\mathrm{N}=25$ & $\mathrm{~N}=25$ & $\mathrm{~N}=25$ \\
& Mean $=5.24$ & Mean $=4.0$ & Mean $=29.47$ \\
& Standard & Standard & Standard \\
& Deviation & Deviation & Deviation \\
& $=3.67$ & $=3.69$ & $=3.71$ \\
\hline
\end{tabular}

$M$ : mastectomy, $M$ \& $R$ : mastectomy and reconstruction, HADS hospital anxiety and depression scale, D: depression, BIS: body image scale, FSFI: female sexual function index

\section{DISCUSSION}

In this study, we evaluate depression and anxiety, body image, and sexual function in post-operative $\mathrm{BCa}$ patients with and without reconstruction in Onkologi Surabaya Hospital. As stated in the study from Archangelo et al. [12] in Brazil, an elapsed time more than one year after breast surgery is used as an inclusion in this study. It is considered as an adequate time to evaluate QoL dan minimize the bias of psychological impact.

Psychological disturbances are common in breast cancer patients. Despite that, there is no significant difference from our study in the anxiety and depression levels in both groups. It is supported by the research from Ardnt et al. [13] which stated that surgical treatment does not have a significant effect on the quality of the patients' lives.

Other than surgical procedures, mixed feelings of fearfulness about disease recurrence could also play a significant role in $\mathrm{BCa}$ patients. Some studies also wrote that the hardship of adapting to a life-changing situation, fear of death, changes in appearance, and anxiety about plans could be the cause of this issue [14]. However, good communication between a surgeon and his patients could escalate patients' coping and managing skills, where the explanation about the journey of disease, therapies, and side effects of therapy are well informed to the patients and their families. A solid support system is also proven to improve adaptation skills and achieve better QoL.

According to the result in our study, patients who received breast reconstruction experienced less disturbance in body image compared to patients with mastectomy only. Mastectomy procedure causes a woman to lose her self-confidence because breasts are related to femininity [15]. In line with this study, Olfatbakhsh et al. [16], using another instrument to analyze body image, found that among three frequent breast cancer operation procedures, patients who have undergone mastectomy have significantly lower social functioning of body image concern inventory (BICI) compared to women with BCS and Mastectomy with Reconstruction.

Systemic therapies of $\mathrm{BCa}$ could intertwine the impact of sexual function in patients. In our study, subjects received chemotherapy ( $M=65 \%, M+R=76 \%$ ), radiotherapy ( $M=29 \%, M+R=36 \%)$, and hormonal therapy $(M=76 \%, M+R=72 \%)$. Cobo-Cuenca et al. [17] from Spain stated that patients who had chemotherapy presented more sexual dysfunction than those who did not, and women who consumed hormonal therapy (e.g., aromatase inhibitors or tamoxifen) also 
showed more negative changes in sexual life. However, we tend to focus on the comparison of surgical procedures. Surgical intervention of BCa was associated with the presence of sexual dysfunction. In our study, a significant difference in sexual function mean value is seen in both groups ( $M=25.47, M+R=29.47$ ). Referring to the FSFI, the value above 26.6 indicates a good sexual function, and it is claimed by the group of women with Reconstruction. Another study from Andrzejczak et al. [21] published that women who had a unilateral or bilateral mastectomy developed more dysfunctions compared to those with lumpectomy [18-20], and patients who received mastectomy alone had the greatest probability of sexual dysfunction.

\section{CONCLUSIONS}

Through this study, superior QoL value in body image and sexual function was found in the group of $\mathrm{BCa}$ patients who received reconstruction procedures. Taking this into account, adequate information about the advantage and disadvantages of both modalities should be well discussed pre-operatively by the surgeon and the patient to plan suitable breast cancer surgery and achieve greater outcomes in QoL.

\section{DECLARATIONS}

\section{Competing of Interest}

The authors declare no competing interest in this study

\section{Ethics Approval}

This research was ethically approved by The Health Research Ethics Committee of Dr. Soetomo Hospital Surabaya in August 2020 No. 0101/LOE/301.4.2/VIII/2020

\section{Acknowledgment}

Our deepest gratitude to dr. Vicky Damayanti, M.Kes, as the director of RSOS, for her constant support. We'd also want to appreciate dr. Jacobus Octovianus, Sp.B, FICS, for his excellent advice and helpful ideas, which have been really beneficial to our research. We also express our gratefulness to dr. Joeti Kartiza Soejono, MPH,MM, and Dr. Sunarjo, dr.,MS,MSc for their valuable guidance. Last, we'd like to show our thanks to the RSOS nurses and staff for their help all throughout this study.

\section{REFERENCES}

1. Youlden DR, Cramb SM, Yip CH, Baade PD. Incidence and mortality of female breast cancer in the Asia Pacific region. Cancer Biol Med. 2014;11(2):101-15.

2. Perry SH, Kowalski TL, Chang $\mathrm{CH}$. Quality of life assessment in women with breast cancer: benefits, acceptability and utilization. Health Qual Life Outcomes. 2007;5:24-38.

3. Somogyi RB, Ziolkowski N, Osman F, et al. Breast reconstruction. Updated overview for primary care physicians. Can Fam Physician. 2018;64(6):424-32.

4. Masjoudi M, Keshavar Z, Akbari ME, Kashani FL. Evaluation of sexual function in breast cancer survivors using Female Sexual Function Index: a systematic review. IJWHR. 2019;7(4):434-41.

5. Rahman GA. Breast conserving therapy: A surgical technique where little can mean more. J Surg Tech Case Rep. 2011;3(1):1-4.

6. Qin $\mathrm{Q}, \operatorname{Tan} \mathrm{Q}$, Lian B, et al. Postoperative outcomes of breast reconstruction after mastectomy. Medicine (Baltimore). 2018;97(5):e9766.

7. King CR. Advances in how clinical nurses can evaluate and improve quality of life for Individuals with cancer. Oncol Nurs Forum. 2006;33(1 suppl):5-12.

8. Zigmond AS, Snaith RP. The hospital anxiety and depression scale. Acta Psychiatr Scand. 1983;67:36170.

9. Hopwood P, Fletcher I, Lee A, Al Ghazal S. A body image scale for use with cancer patients. Eur J Cancer. 2001;37(2):189-97.

10. Rosen R, Brown C, Heiman J, et al. Female Sexual Function Index (FSFI). J Sex Marital Ther. 2000;26(2):191-208.

11. Fingeret MC, Teo I, Epner DE. Managing body image difficulties of adult cancer patients: Lessons from available research. Cancer. 2014;120(5):633-41.

12. Archangelo SCV, Sabino Neto M, Veiga DF, et al. Sexuality, depression and body image after breast reconstruction. Clinics (Sao Paulo). 2019;74:e883.

13. Arndt V, Merx H, Stegmaier C, et al. Persistence of restrictions in quality of life from the first to the third year after diagnosis in women with breast cancer. J Clin Oncol. 2005;23(22):4945-53.

14. The American Cancer Society. Breast Cancer [internet]. Atlanta: Cancer.org; 2014 [cited 2015 Jan 15]. Available from: http://www.cancer.org/Cancer/ BreastCancer/

15. Izadi-Ajirlo A, Bahmani B, Ghanbari-Motlagh A. Effectiveness of cognitive behavioral group intervention on body image improving and increasing self-esteem in women with breast cancer after mastectomy. Arch Rehabil. 2013;13(4):72-83.

16. Olfatbakhsh A, Mehrdad N, Ebrahimi $M$, et al. Evaluation of factors impacting cosmetic outcome of breast conservative surgery--a study in Iran. Asian Pac J Cancer Prev. 2015;16(6):2203-7.

17. Cobo-Cuenca Al, Martín-Espinosa NM, SampietroCrespo A, et al. Sexual dysfunction in Spanish women with breast cancer. PLOS ONE. 2018;13(8):e0203151.

18. Alicikus ZA, Gorken IB, Sen RC, et al. Psychosexual and body image aspects of quality of life in Turkish 
breast cancer patients: a comparison of breast conserving treatment and mastectomy. Tumori. 2009;95(2):212-18.

19. Aerts L, Christiaens M, Enzlin P, et al. Sexual functioning in women after mastectomy versus breast conserving therapy for early-stage breast cancer: a prospective controlled study. Breast. 2014;23(5):629-36.
20. Raggio GA, Butryn ML, Arigo D, et al. Prevalence and correlates of sexual morbidity in long-term breast cancer survivors. Psychol Health. 2014;29(6):632-50.

21. Andrzejczak E, Markocka-Mączka K, Lewandowski A. Partner relationships after mastectomy in women not offered breast reconstruction. Psychooncology. 2013;22(7):1653-7. 